\title{
Population genetics of Anopheles arabiensis, the primary malaria vector in the Republic of Sudan
}

\author{
Mashair Sir El Khatim Mustafa ${ }^{*}$, Zairi Jaal ${ }^{2}$, Sumia Abu Kashawa ${ }^{3}$ and Siti Azizah Mohd Nor ${ }^{4}$
}

\begin{abstract}
Background: Anopheles arabiensis is a member of Anopheles gambiae complex and the main malaria vector in Sudan. There is insufficient population genetics data available on An. arabiensis for an understanding of vector population structure and genetics, which are important for the malaria vector control programmes in this country. The objective of this investigation is to study the population structure, gene flow and isolation by distance among An. arabiensis populations for developing control strategies.
\end{abstract}

Methods: Mosquitoes were collected from six sites located in three different states in Sudan, Khartoum, Kassala and Sennar, using pyrethrum spray catch of indoor resting mosquitoes. Anopheline mosquitoes were identified morphologically and based on species specific nucleotide sequences in the ribosomal DNA intergenic spacers (IGS). Seven published An. gambiae microsatellite loci primers were used to amplify the DNA of An. arabiensis samples.

Results: PCR confirmed that An. arabiensis was the main malaria vector found in the six localities. Of the seven microsatellite loci utilized, six were found to be highly polymorphic across populations, with high allelic richness and heterozygosity with the remaining one being monomorphic. Deviation from Hardy-Weinberg expectations were found in 21 out of 42 tests in the six populations due to heterozygote deficiency. Bayesian clustering analysis revealed two gene pools, grouping samples into two population clusters; one includes four and the other includes two populations. The clusters were not grouped according to the three states but were instead an admixture. The genetic distances between pairs of populations ranged from 0.06 to 0.24 . Significant $F_{S T}$ was observed between all pairwise analyses of An. arabiensis populations. The Kassala state population indicated high genetic differentiation $\left(\mathrm{F}_{\mathrm{ST}}\right.$ ranged from 0.17 to 0.24 ) from other populations, including one which is also located in the same state. High gene flow $(\mathrm{Nm}=1.6-8.2)$ was detected among populations within respective clusters but limited between clusters particularly with respect to Kassala state. There was evidence of a bottleneck event in one of the populations (Al Haj Yousif site). No isolation by distance pattern was detected among populations.

Conclusions: This study revealed low levels of population differentiation with high gene flow among the An. arabiensis populations investigated in Sudan, with the exception of Kassala state.

Keywords: Anopheles arabiensis, Microsatellite loci, Population genetic, Gene flow, Bottleneck, Sudan

*Correspondence: mashairm@hotmail.com

${ }^{1}$ Department of Biology \& Chemistry, Al Butana University, 200, Rufaa, Sudan

Full list of author information is available at the end of the article

\section{Background}

In Sudan, malaria remains as one of the most important public health problems. More than 400 species of Anopheles have been recognized globally and, of these, 41 species can transmit malaria but only a few of them are malaria vectors [1]. With the exception of Southern 
Sudan, the main malaria vector in Sudan is Anopheles arabiensis [2-9]. However, in Southern Sudan Anopheles gambiae and Anopheles funestus are the major vectors of malaria and their vectorial capacity may be similar to that of An. arabiensis [1]. This species is a highly adaptable species with the capability to feed on multiple host species, both indoors and outdoors and acclimatize to a wide range of larval habitats $[10,11]$. At present, indoor residual spraying (IRS) and insecticide treated bed nets (ITNs) are the main methods extensively used for vector control worldwide. These methods have proven valuable in reducing malaria burden [12, 13], but their usefulness has been threatened by increasing prevalence of insecticide resistance in the most important malaria vectors, including An. arabiensis. Thus, there is an urgent need for effective and sustainable alternatives to these traditional vector control strategies.

Microsatellites are genetic markers of short tracts of tandemly repeated DNA sequences. These markers have become the genetic marker of choice for studying the population genetics of many eukaryotic species, including mosquitoes. For instance, they have been widely utilized in such studies in the An. gambiae complex [14-20]. They have been developed into PCR-based molecular markers that are very useful for small organisms with limited extractable DNA [21].

To date, 150 polymorphic microsatellite loci have been characterized in An. gambiae sensu lato (s.l.) [14, 22], which have been widely used to explain the population structure and gene flow within and between members of the An. gambiae complex [23-25]. Most of these studies have been conducted on An. gambiae with some limited data on An. arabiensis. Present literature on An. arabiensis has revealed the lack of subpopulation differentiation in relation to larval habitat utilization [24]. Lack of annual bottlenecks in response to changes in the environment has also been documented [17, 26]. Large effective population size and/or recent range expansion as opposed to group migration $[26,27]$ have been attributed to the lack of population structuring. This is based on several experimental studies which have reported a short flight range for this malaria vector species [28] among villages in The Gambia. On the other hand, there is evidence in support of population structuring [29] from West Africa and eastern outer islands [27] of Eastern Africa. Furthermore, limited gene flow has been observed between the west and south east of the Rift Valley and in Southern Zambia [17, 23], respectively. Geographic distance and habitat alterations have been suggested as the main contributors of genetic isolation.

Anopheles arabiensis has changeable deme sizes ranging from as low as $25 \mathrm{~km}$ [27] to a few $1000 \mathrm{kms}$ [17]. It was observed that in the Mwea Rice Scheme of Central
Kenya, An. arabiensis mosquito densities decrease with increasing distance from the scheme $[30,31]$. On the contrary, the human blood index [10] in addition to malarial transmission [30] by this species were significantly lower inside than in the outer areas of the rice scheme. All these factors influence mosquito reproductive fitness, survivorship and fertility [32]. Such alteration may change malarial transmission indices [33] and can lead to subpopulation differentiation [34-36] as was observed in this agricultural scheme. Moreover, the lack of evident geographical barriers that could have restricted gene flow between mosquito populations in the surrounding areas had led to the generation of a single panmictic population. A number of studies, for example one that was conducted by Dolo et al. [34] in the irrigated area of Sahel in Mali had suggested that the existence of mosquito colonies in an adjoining non-irrigated area during the dry season was maintained through migration of a few individuals from the irrigated areas.

Several comparative population studies between $A n$. arabiensis and An. gambiae have shown a higher level of genetic differentiation in the latter species. Significant genetic differentiation, $\mathrm{F}_{\mathrm{ST}}=0.072-0.100$ were observed for An. gambiae populations between western Kenya and coastal Kenya using microsatellite markers. Lehmann et al. $[35,36]$ suggested the Great Rift Valley as a major gene flow barrier for this species. However, non-significant genetic differentiation was identified for An. arabiensis populations from the two areas using the same loci [23]. Similarly, Donnelly and Townson [25] noted non-significant genetic differentiation of $A n$. arabiensis populations in Malawi and Sudan. It thus appeared that different mechanisms of gene movement were in operation between the two species. Considering An. gambiae, these studies were discordant with another study on $A n$. gambiae sensu stricto (s.s.) (mean $\mathrm{F}_{\mathrm{ST}}=0.006$ ), which was genetically non differentiated across the $6650 \mathrm{~km}^{2}$ of the Kilombero valley landscape southern Tanzania. This suggested that the genetic differentiation in other populations was not due to physical barriers or distance. One plausible explanation is that there was environmental diversification even within the Kilombero valley [19]. Thus, the differentiated populations of An. gambiae could have been maintained by some degree of reproductive isolation.

With respect to An. arabiensis, several studies have reported varying levels of genetic differentiation. Nyanjom et al. [13] detected low $\mathrm{F}_{\mathrm{ST}}$ but statistically significant genetic structure for An. arabiensis populations in Ethiopia and Eritrea. On the other hand, Simard et al. [24] reported high levels of genetic differentiation in two island populations of $A n$. arabiensis populations that were $240 \mathrm{~km}$ apart in the Indian Ocean $\left(\mathrm{F}_{\mathrm{ST}} 0.080-0.215\right)$. 
High levels of genetic differentiation were also detected among An. arabiensis populations (mean $\mathrm{F}_{\mathrm{ST}}=0.066$ ) in Kilombero valley southern Tanzania [19].

Therefore, the objective of this investigation was to study the population structure and gene flow among An. arabiensis populations in Sudan based on microsatellite markers which may assist in developing control strategies.

\section{Methods}

\section{Study areas}

A total of 200 specimens of $A n$. arabiensis were collected from June 2010 to May 2011 from six different localities in Sudan representing different ecological zones separated by the River Nile and its tributaries (Fig. 1). Three localities were located in Khartoum State: (1) Mygoma
(My), (2) Al Haj Yousif (Hj), and (3) El Gerif West (Gw). $\mathrm{My}$ and $\mathrm{Hj}$ are nearest to each other and located east of the Blue Nile. Al Haj Yousif $(\mathrm{Hj})$ is northeast of Helt Koko, where animals are bred for milk production in a rich green area on the west bank of the Blue Nile. Two localites were located in Kassala State: (4) Alhalang Shemal (H.sh), an area of non-agricultural land on the east bank of the Al Gash River and (5) Alkrmota $(\mathrm{Kr})$ on the west bank of the Al Gash River in the centre of an agricultural area which is surrounded by groves of fruit and vegetables. The sixth population was located in the Sennar state (Se): (6) Abu Algoni (Se), a farming area on the west bank of the Blue Nile River. Khartoum is the most central among the three regions while Kassala is in eastern Sudan with Sennar lying between the two, further south. The Blue Nile flows along Khartoum and Sennar

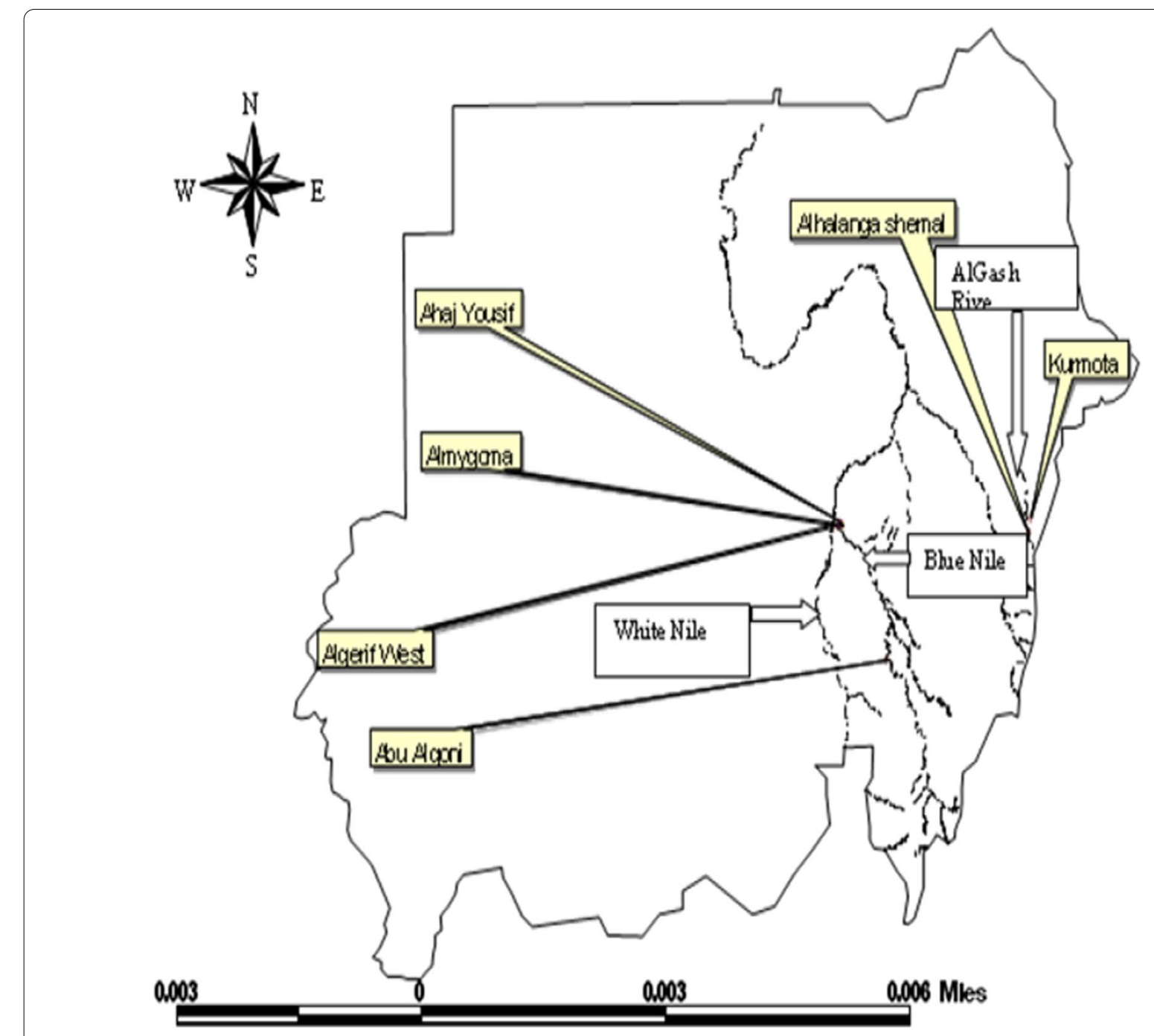

Fig. 1 Study areas 
while its tributary the Al Gash River flows along Kassala. The pairwise geographical distances between the six localities ranged from 3.93 to $569.25 \mathrm{~km}$.

\section{Microsatellite PCR amplification}

Molecular classification of An. gambiae species complex in this study was conducted based on the ribosomal DNA intergenic spacers (IGS) [37]. DNA extraction from individual Anopheles was conducted using the DNeasy blood and Tissue E kit (QIAGEN, Valencia, CA). Seven published An. gambiae microsatellite loci primers [12] were used to amplify the DNA samples. The PCR reactions were performed in a gradient thermal cycler (MJ Research PTC-200 Peltier Thermal Cycler) for 30 cycles. The PCR mix contained $1 \mathrm{uL}$ of genomic DNA, $5 \times$ PCR buffer (Promega, Madison, WI), 15 pmol of each fluorescent labelled (NED, HEX or FAM) forward primer, $200 \mathrm{mmol}$ each dATP, dCTP, dGTP and dTTP, $1.2 \mathrm{uL}$ of $25 \mathrm{~mm} \mathrm{MgCl}_{2}$ and $0.5 \mathrm{U}$ Taq DNA polymerase (Promega, Madison, WI) in a $20 \mathrm{uL}$ total reaction volume. Singleplex PCR amplification was conducted for loci AGXH678, AG2H290, AG2H603, AG2H143, AG3H29, AG3H45, AG3H158 (Table 1). The thermal cycling conditions were; an initial hold at $95^{\circ} \mathrm{C}$ for $2 \mathrm{~min}$, followed by 30 cycles of $94{ }^{\circ} \mathrm{C}$ for $30 \mathrm{~s}, 55^{\circ} \mathrm{C}$ for $30 \mathrm{~s}$ and $72{ }^{\circ} \mathrm{C}$ for $30 \mathrm{~s}$ and a final extension at $72{ }^{\circ} \mathrm{C}$ for $5 \mathrm{~min}$. Satisfactory PCR products as detected in a $2 \%$ agarose gel were sent to the service provider (First BASE Laboratories
Sdn. Bhd., Selangor, Malaysia) into two primer multiplex sets for fragment analysis. Set A contained a mixture of AGXH678, AG2H290 and AG3H45, while set B was a mixture of AG2H603, AG2H143, AG3H29 and AG3H158. Loci AGXH678, AG3H29, AG3H45 and AG3H158 are found outside the inversion regions of the chromosome, while AG2H603 and AG2H143 loci are found within fixed inversion of chromosome $2 \mathrm{La}$, and AG2H 290 in the 2R polymorphic inversion.

\section{Data analysis}

Allelic data scoring of alleles was carried out by inspection of the electrophoretograms as described in Arif et al. [38]. Two well-resolved peaks indicate a heterozygous individual while presence of a single main peak represent a homozygous individual. Minor bands or stutters are also often present but being non alleles, were not included in the input data. Screening of all the genotypic data was executed using Micro-Checker v2.2.3 [39] to check for presence of null alleles and stuttering or large allele dropouts. The Monte Carlo simulation method was applied to generate expected homozygote and heterozygote frequencies of alleles. The HWE analysis was used to assess deviation from expected allele frequencies and the frequency of any null allele detected with significance level at $\mathrm{p}<0.05$ obtained through 1000 permutations. To ensure compatibility with different software analyses the raw data

Table 1 Allelic richness $\left(A_{R}\right)$, number of alleles $\left(N_{A}\right)$, and the mean allele number of observed $\left(H_{O}\right)$ and expected heterozygosity $\left(H_{E}\right)$ at each locus per population

\begin{tabular}{|c|c|c|c|c|c|c|c|c|}
\hline Locus & Pop & Gw & H.sh & $\mathrm{Hj}$ & My & $\mathrm{Se}$ & $\mathrm{Kr}$ & Total \\
\hline & $N$ & 33 & 34 & 32 & 34 & 33 & 34 & 200 \\
\hline \multirow[t]{2}{*}{ AGXH678 } & $A_{R}$ & 2 & 6 & 1 & 8 & 7 & 7 & 8 \\
\hline & $N_{A}$ & 3 & 4 & 2 & 5 & 5 & 4 & 7 \\
\hline \multirow[t]{2}{*}{ AG2H290 } & $A_{R}$ & 1 & 3 & 2 & 3 & 3 & 3 & 3 \\
\hline & $N_{A}$ & 2 & 4 & 3 & 4 & 4 & 4 & 4 \\
\hline \multirow[t]{2}{*}{ AG2H603 } & $A_{R}$ & 3 & 6 & 4 & 4 & 4 & 4 & 6 \\
\hline & $\mathrm{N}_{\mathrm{A}}$ & 4 & 7 & 5 & 5 & 5 & 5 & 7 \\
\hline \multirow[t]{2}{*}{ AG2H143 } & $A_{R}$ & 6 & 12 & 6 & 10 & 12 & 12 & 15 \\
\hline & $\mathrm{N}_{\mathrm{A}}$ & 4 & 5 & 4 & 4 & 7 & 7 & 13 \\
\hline \multirow[t]{2}{*}{ AG3H29 } & $A_{R}$ & - & 1 & - & - & - & 1 & 1 \\
\hline & $N_{A}$ & - & 2 & - & - & - & 2 & 2 \\
\hline \multirow[t]{2}{*}{ AG3H45 } & $A_{R}$ & 10 & 10 & 4 & 9 & 10 & 10 & 13 \\
\hline & $\mathrm{N}_{\mathrm{A}}$ & 6 & 5 & 3 & 7 & 6 & 5 & 13 \\
\hline \multirow[t]{2}{*}{ AG3H158 } & $A_{R}$ & 4 & 4 & 4 & 4 & 5 & 6 & 6 \\
\hline & $\mathrm{N}_{\mathrm{A}}$ & 3 & 3 & 3 & 3 & 5 & 5 & 7 \\
\hline \multirow[t]{4}{*}{ Mean } & $A_{R}$ & 4.3 & 6 & 3.5 & 6.3 & 6.8 & 6.1 & 7.4 \\
\hline & $N_{A}$ & 3.7 & 4.3 & 3.3 & 4.7 & 5.3 & 4.6 & 7.6 \\
\hline & $\mathrm{H}_{\mathrm{O}}$ & 0.55 & 0.55 & 0.6 & 0.63 & 0.67 & 0.63 & 0.61 \\
\hline & $H_{E}$ & 0.57 & 0.55 & 0.56 & 0.62 & 0.59 & 0.61 & 0.58 \\
\hline
\end{tabular}


was converted into several specific data formats using CONVERT [40]. Significant relationship between alleles at any two loci was tested using the likelihood ratio test of linkage disequilibrium based on Expectation-Maximization (EM) algorithm [41]. This was applied to all pairwise comparisons of loci using Arlequin version 3.11 [42] with 10,000 permutations followed by false discovery rate (FDR) adjustment [43] at 95\% significant level.

Population genetic diversity was measured based on allelic richness $\left(A_{R}\right)$, adjusted for different sample size and number of alleles $\left(\mathrm{N}_{\mathrm{A}}\right)$. To test for global deviation from HWE in a population, the inbreeding coefficient, $\left(\mathrm{F}_{\mathrm{IS}}\right)$ for each locus and population [44] was estimated in FSTAT v.2.9.3 [45]. Mean genetic heterozygosity, observed $\left(H_{O}\right)$ and expected $\left(H_{E}\right)$ heterozygosities per locus and population were estimated over all loci. Testing of deviation from Hardy-Weinberg equilibrium (HWE) was conducted using the exact tests with 10,000 steps in Markov chain and 10,000 dememorization steps in Arlequin version 3.11 [42]. Multiple testing of HWE was adjusted using False discovery rate (FDR) corrections with a global significance level of 0.05 .

Estimates of population differentiation, using Wrights $\mathrm{F}_{\mathrm{ST}}$ [46] over all loci were conducted. $\mathrm{F}_{\mathrm{ST}}$ is based on the infinite allele model (IAM) which hypothesizes that each new allele is generated at a given rate, $\mu$ [47].

The program BOTTLENECK V 1.2.02 [48] was used to detect whether the populations had experienced recent effective population size reduction. Two-phase (TPM) models, infinite allele (IAM) and stepwise mutation (SMM), and deviation from HWE was estimated using a two-tailed Wilcoxon sign-rank test followed by FDR adjustment. Qualitative descriptor of allele frequency ("mode-shift" indicator) was also performed in BOTTLENECK to discriminate "shifted mode" populations (bottleneck) from stable populations [48]. Mantel test was used to investigate the correlation between geographical and genetic distances among populations using Arlequin 3.11 [42].

Assignment of individuals to their respective source populations based on multilocus genotypic data was determined in STRUCTURE version 2.3 [49]. An assumption of correlated allele frequency among populations [49] and admixture model was used with the burn in period of 10,000 and MCMC length of 10 iterations. The probabilities of genotype assignment into each individual group were performed across replicates using CLUMPP version 1.1.2 [50] and the graphical presentation was carried out using Structure Harvester [51]. Ten independent runs were computed for all possible values of the maximum number of clusters $(K=6)$. Finally, based on genetic distance a neighbour-joining tree was constructed to determine the phylogenetic tree among the six populations using MEGA 5.0.5 [52].

\section{Results}

All 200 individuals from six populations of An. arabiensis in Sudan were successfully genotyped and scored for all seven microsatellite loci. No evidence for scoring error due to null alleles, large allele dropout or stuttering was detected after assessing with Microchecker.

\section{Allelic frequency distribution and linkage disequilibrium}

All (except one) microsatellite markers of An. arabiensis populations were found to be polymorphic in at least one population. However, locus AG3H29 was monomorphic in most populations. Loci AG2H143 and AG3H45 were moderately polymorphic with number of alleles per locus ranging from 6-12 and 4-10, respectively. The total number of alleles per locus ranged from 2 to 12 with an average of 7.6. The mean $A_{R}$ ranged from a minimum of $3.5 \mathrm{in} \mathrm{Hj}$ (Khartoum State) to a maximum of 6.8 in Se (Sennar State) and the means observed heterozygosity of alleles per locus ranged from 0.55 to 0.67 , while means of expected heterozygosity ranged from 0.55 to 0.62 (Table 1 and Fig. 2). Tests for linkage disequilibrium revealed that 14 pairwise comparisons (11.11\% out of 126 pairwise comparisons) after Bonferroni correction were significantly deviated from the random association of alleles at two or more loci with the highest linkage disequilibrium detected from pairwise loci comparisons in $\mathrm{Kr}$ (5 pairs in loci AGXH678, AG2H290, AG2H143 and AG3H158), followed by My (4 in loci AGXH678, AG2H290, AG2H603 and AG2H143), H.sh (2 pairs in loci AG2H290, AG2H603), $\mathrm{Hj}$ (1 pair in AG3H158) and Se (2 pairs in loci AGXH678 and AG2H143). No linkage disequilibrium of loci was observed in $\mathrm{Gw}$.

\section{Hardy-Weinberg equilibrium (HWE) and FIS}

Each population was tested separately for significant departure from HWE at each locus. Observed heterozygosity varied from 0.12 to 0.94 while expected heterozygosity ranged from 0.11 to 0.76 (Table 2). Deviations from HWE were found in 21 out of 42 tests in the six populations. These were observed in locus AGXH678 (Gw and H.sh), locus AG2H290 (H.sh, Hj, My and $\mathrm{Kr}$ ), locus AG2H603 (Gw, H.sh, $\mathrm{Hj}$, My and $\mathrm{Kr}$ ) locus AG2H143 (Gw, Hj, My and Se), locus AG3H45 (H.sh, Hj, My, Se and $\mathrm{Kr}$ ) and locus AG3H158 in Kr. Thus, there was no consistent pattern according to locus or population and fairly equal numbers of heterozygote deficiencies and heterozygote excess were observed. Based on the Microchecker results, these deviations were presumably due to population subdivision rather than the existence of null alleles. Locus AG3H29 showed no deviations from 


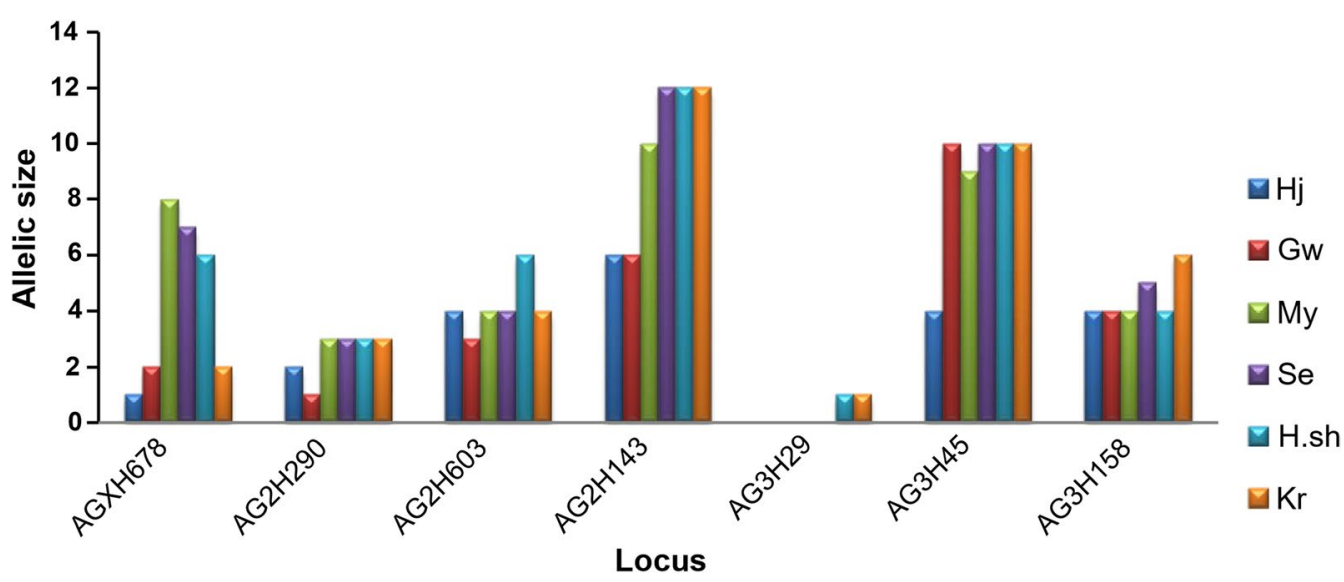

Fig. 2 Number of alleles observed in each locus for each population

Table 2 Population genetic diversity as measured by observed $\left(H_{O}\right)$ and expected $\left(H_{E}\right)$ heterozigosities and $\mathrm{F}_{\mathrm{IS}}$

\begin{tabular}{|c|c|c|c|c|c|c|c|}
\hline & Pop & Gw & H.sh & $\mathrm{Hj}$ & My & Se & $\mathrm{Kr}$ \\
\hline Locus & No & 33 & 34 & 32 & 34 & 33 & 34 \\
\hline \multirow[t]{4}{*}{ AGXH678 } & $\mathrm{H}_{\mathrm{O}}$ & 0.49 & 0.85 & 0.44 & 0.63 & 0.58 & 0.64 \\
\hline & $\mathrm{HE}$ & 0.53 & 0.65 & 0.48 & 0.63 & 0.60 & 0.53 \\
\hline & $F_{1 S}$ & 0.09 & -0.32 & 0.08 & 0.01 & 0.04 & -0.20 \\
\hline & $P$ & $0.03^{*}$ & $0.00^{*}$ & 0.71 & 0.18 & 0.16 & 0.19 \\
\hline \multirow[t]{4}{*}{ AG2H290 } & $\mathrm{HO}$ & 0.61 & 0.50 & 0.53 & 0.56 & 0.70 & 0.67 \\
\hline & $\mathrm{HE}$ & 0.49 & 0.63 & 0.60 & 0.61 & 0.70 & 0.65 \\
\hline & $F_{1 S}$ & -0.26 & 0.21 & 0.12 & 0.08 & 0.01 & -0.03 \\
\hline & $P$ & 0.27 & $0.00^{*}$ & $0.03^{*}$ & $0.00^{*}$ & 0.10 & $0.00^{*}$ \\
\hline \multirow[t]{4}{*}{ AG2H603 } & $\mathrm{H}_{\mathrm{O}}$ & 0.61 & 0.65 & 0.69 & 0.84 & 0.79 & 0.75 \\
\hline & $\mathrm{HE}$ & 0.70 & 0.68 & 0.73 & 0.76 & 0.72 & 0.77 \\
\hline & $F_{1 S}$ & 0.14 & 0.05 & 0.06 & -0.11 & -0.10 & 0.03 \\
\hline & P & $0.00^{*}$ & $0.00^{*}$ & $0.00^{*}$ & $0.00^{*}$ & 0.12 & $0.00^{*}$ \\
\hline \multirow[t]{4}{*}{$\mathrm{AG} 2 \mathrm{H} 143$} & $\mathrm{H}_{\mathrm{O}}$ & 0.58 & 0.62 & 0.88 & 0.67 & 0.55 & 0.58 \\
\hline & HE & 0.65 & 0.68 & 0.61 & 0.51 & 0.50 & 0.63 \\
\hline & $F_{1 S}$ & 0.12 & 0.09 & -0.44 & -0.30 & -0.08 & 0.07 \\
\hline & $P$ & $0.001^{*}$ & 0.20 & $0.00^{*}$ & $0.00^{*}$ & $0.02^{*}$ & 0.38 \\
\hline \multirow[t]{4}{*}{ AG3H29 } & $\mathrm{H}_{\mathrm{O}}$ & - & 0.12 & - & - & - & 0.08 \\
\hline & $\mathrm{HE}$ & - & 0.11 & - & - & - & 0.08 \\
\hline & $F_{1 S}$ & - & -0.05 & - & - & - & -0.03 \\
\hline & P & - & 1 & - & - & - & 1 \\
\hline \multirow[t]{4}{*}{ AG3H45 } & $\mathrm{H}_{\mathrm{O}}$ & 0.52 & 0.53 & 0.75 & 0.69 & 0.58 & 0.94 \\
\hline & HE & 0.50 & 0.63 & 0.55 & 0.74 & 0.70 & 0.76 \\
\hline & $F_{1 S}$ & -0.04 & -0.35 & 0.16 & -0.32 & -0.27 & -0.05 \\
\hline & P & 0.73 & $0.00^{*}$ & $0.01^{*}$ & $0.00^{*}$ & $0.00^{*}$ & $0.00^{*}$ \\
\hline \multirow[t]{4}{*}{ AG3H158 } & $\mathrm{H}_{\mathrm{O}}$ & 0.49 & 0.59 & 0.31 & 0.66 & 0.58 & 0.72 \\
\hline & HE & 0.53 & 0.44 & 0.37 & 0.50 & 0.46 & 0.69 \\
\hline & $F_{1 S}$ & 0.09 & -0.35 & 0.16 & -0.32 & -0.27 & -0.05 \\
\hline & $P$ & 0.22 & 0.09 & 0.07 & 0.09 & 0.20 & $0.00^{*}$ \\
\hline
\end{tabular}

$H_{O}=$ observed heterozygosity $H_{E}=$ expected heterozygosity, $F_{1 S}=$ inbreeding coefficient, high positive values indicate deficiency of heterozygotes, while small or negative values indicate excess of heterozygotes

$p=$ significance of deviation from HWE $(p<0.05),{ }^{*}=$ significant deviation from HWE 
Hardy-Weinberg equilibrium and this locus was monomorphic in all populations except in $\mathrm{H}$.sh and $\mathrm{Kr}$ populations (both in Kassala State). Inbreeding coefficient $\left(\mathrm{F}_{\mathrm{IS}}\right)$ over all loci showed that most of the populations had high excess of heterozygosity (negative $\mathrm{F}_{\mathrm{IS}}$ negative values indicate no inbreeding).

\section{Genetic structure}

A hierarchical AMOVA performed after defining into three groups (Khartoum, Sennar and Kassala) revealed that $2.75 \%$ of the total genetic variance $\left(\mathrm{F}_{\mathrm{CT}}\right)$ was contributed by 'among groups' variation, $13.61 \%\left(\mathrm{~F}_{\mathrm{SC}}\right)$ was 'among populations within group' variation (Table 3) while $83.63 \%$ was attributed to 'between individuals within population' i.e. intrapopulation variation. All hierarchical levels i.e. $\mathrm{F}_{\mathrm{SC}}$ and $\mathrm{F}_{\mathrm{CT}}$ and 'within population' revealed significant variation $(\mathrm{p}<0.05)$.

Significant differentiation among populations, $\left(\mathrm{F}_{\mathrm{ST}}\right)$ was observed between all An. arabiensis pairwise comparisons for all loci (Table 4, $\mathrm{p}<0.05$ ). $\mathrm{F}_{\mathrm{ST}}$ ranged from 0.06 to 0.24 . But if $\mathrm{Kr}$ is excluded, and in most cases, Se as well, the comparisons will indicate moderate genetic differentiation for all. Moderate genetic differentiation was observed between An. arabiensis populations from My (Khartoum State) and Se (Sennar State) $\left(\mathrm{F}_{\mathrm{ST}}=0.06\right)$ and $\mathrm{Gw}$ (Khartoum State) and H.sh (Kassala state) $\left(\mathrm{F}_{\mathrm{ST}}=0.08\right)$. However, high genetic differentiation was observed between An. arabiensis populations from $\mathrm{Kr}$ and other populations $\mathrm{F}_{\mathrm{ST}}=0.17-0.24$ including with H.sh which is also in the same state of Kassala. Thus, although the detailed magnitudes of population differentiation vary among population comparisons in the various analyses, in summary $\mathrm{Kr}$ is most distant or differentiated from other populations and followed by Se to a certain extent for several pairwise comparisons.

Gene flow $(\mathrm{Nm})$ calculated from mean $\mathrm{F}_{\mathrm{ST}}$ statistics ranged from 1.5 to 9.05 suggesting high gene flow between populations (Table 5) except for those involving $\mathrm{Kr}$. For example, high gene flow was detected among Se (Sennar State) with My and Gw (both Khartoum State); Hj and My (both Khartoum State). Very little gene flow was observed between $\mathrm{Kr}$ (Kassala State)

Table 3 Results of AMOVA of Anopheles arabiensis populations inferred by microsatellite markers

\begin{tabular}{lclcll}
\hline Source of variation & d.f & Variance components & Percentage of variation & Fixation indices & $p$ value \\
\hline Among groups & 2 & 0.06 & 2.75 & $\mathrm{~F}_{\mathrm{CT}}: 0.16$ & $<0.001$ \\
$\begin{array}{l}\text { Among populations within } \\
\text { groups }\end{array}$ & 3 & 0.30 & 13.61 & 0.14 & $<0.001$ \\
Within population & 394 & 1.84 & 83.63 & 0.03 & 0.003 \\
\hline
\end{tabular}

Table 4 Population differentiation of Anopheles arabiensis as estimated using Wright's pairwise $\mathrm{F}_{\mathrm{ST}}$

\begin{tabular}{llllll}
$*$ & & & & & \\
Gw & $*$ & & & & \\
$\mathrm{H} . \mathrm{sh}$ & 0.08 & $*$ & $*$ & $*$ & $*$ \\
$\mathrm{Hj}$ & 0.11 & 0.12 & 0.11 & 0.06 & 0.19 \\
$\mathrm{My}$ & 0.13 & 0.11 & 0.17 & 0.21 & $*$ \\
$\mathrm{Se}$ & 0.18 & 0.16 & 0.24 & & \\
$\mathrm{Kr}$ & 0.22 & 0.17 & & & \\
\hline
\end{tabular}

Table 5 Gene flow estimates between populations of Anopheles arabiensis in Sudan

\begin{tabular}{|c|c|c|c|c|c|c|}
\hline 0 & Gw & H.sh & $\mathrm{Hj}$ & My & $\mathrm{Se}$ & $\mathrm{Kr}$ \\
\hline Gw & 0 & 426.5 & 5.38 & 15.55 & 323.1 & 443.21 \\
\hline H.sh & 5.89 & 0 & 448.59 & 416.55 & 429.31 & 12.88 \\
\hline $\mathrm{Hj}$ & 4.06 & 3.51 & 0 & 3.93 & 311.55 & 427.72 \\
\hline My & 3.48 & 4.07 & 3.81 & 0 & 292.07 & 431.75 \\
\hline $\mathrm{Se}$ & 2.22 & 2.71 & 2.47 & 9.05 & 0 & 334.01 \\
\hline $\mathrm{Kr}$ & 1.69 & 2.30 & 1.50 & 1.88 & 1.97 & 0 \\
\hline
\end{tabular}

Geographical distance $(\mathrm{km})$ between sites

$\mathrm{Nm}$, gene flow between An. arabiensis populations 
and other populations. When considering the loci outside the inversion (AGXH678, AG3H29, AG3H45 and AG3H158), $\mathrm{F}_{\mathrm{ST}}$ statistics ranged from 0.026 to 0.32 with mean $F_{\mathrm{ST}}=0.13$. For loci inside inversion (AG2H603; AG2H290 and AG2H143), $\mathrm{F}_{\mathrm{ST}}$ ranged from 0.019 to 0.20 with mean $F_{\mathrm{ST}}=0.16$. Gene flow $(\mathrm{Nm})$ for loci outside the chromosomal inversions ranged from 1.04 to 43.52. The highest gene flow was between My and H.sh with $\mathrm{Nm}=43.52$, while little gene flow was found between $\mathrm{Kr}$ and $\mathrm{Hj}$ with $\mathrm{Nm}=1.04$. For loci inside the fixed chromosomal inversion, $2 \mathrm{La}$, a range of $\mathrm{Nm}=1.38$ to 19.99 was observed, with the highest gene flow between Se and My with $\mathrm{Nm}=19.99$, while little gene flow was detected between $\mathrm{Se}$ and $\mathrm{Kr}$ with $\mathrm{Nm}=1.38$.

\section{Population bottleneck}

The Wilcoxon test (Table 6) indicated that all populations excluding Se were significant for IAM mutationdrift equilibrium $(\alpha<0.05)$, but with normal L-shaped distribution. This shows that these populations had not experienced population bottleneck. However, population $\mathrm{Hj}$ (Khartoum State) with shifted mode suggest recent population size reduction. TPM analysis showed nonsignificance for all populations except $\mathrm{Hj}$ while the SMM analysis showed non significance for all populations.

Although there was significant differentiation, $\mathrm{F}_{\mathrm{ST}}$, between the different populations, Mantel tests showed no significant correlation $\left(\mathrm{r}^{2}=0.09, \mathrm{p}>0.05\right)$ between genetic differentiation measured as linearized $\mathrm{F}_{\mathrm{ST}}\left(\mathrm{F}_{\mathrm{ST}} /\right.$ $\left(1-\mathrm{F}_{\mathrm{ST}}\right)$ and geographic distance $(\mathrm{km})$ (Fig. 3). Thus, genetic and geographic distances are not correlated.

\section{Population structure}

Based on the programme STRUCTURE after calculations of the delta $K$ and plotting its value against the assumed number of populations $(\mathrm{K}=6)$, a peak at $K=2$ revealed two main clusters (Fig. 4). The dataset was further analysed by assigning individuals between the two suggested clusters. Figure 5 explains the analysis for assignment of the most likely $\mathrm{K}(K=2)$. This analysis is in

Table 6 Bottleneck analysis of An. arabiensis populations from six areas in Sudan

\begin{tabular}{lllll}
\hline Area & IAM & TPM & SMM & Mode-shift \\
\hline Hj $(n=32)$ & 0.016 & 0.031 & 0.109 & Shifted \\
Gw $(n=33)$ & 0.031 & 0.438 & 0.438 & Normal \\
My $(n=34)$ & 0.047 & 0.438 & 0.844 & Normal \\
Se $(n=33)$ & 0.078 & 0.563 & 0.563 & Normal \\
H.sh $(n=34)$ & 0.039 & 0.375 & 0.299 & Normal \\
Kr $(n=34)$ & 0.023 & 0.055 & 0.688 & Normal \\
\hline
\end{tabular}

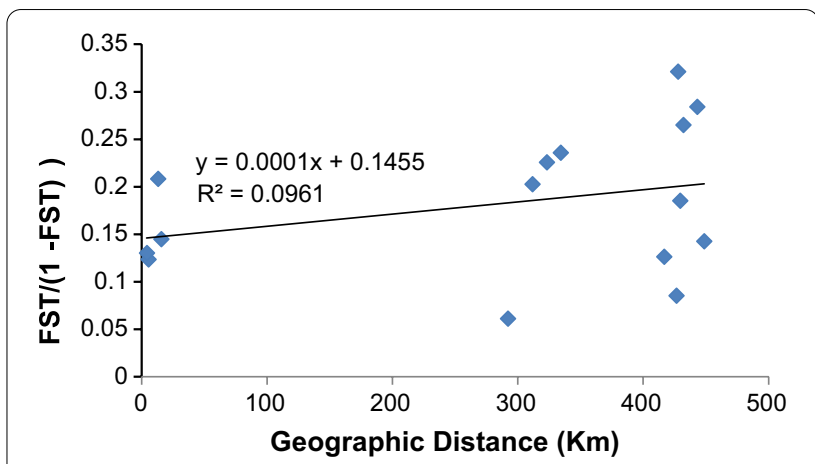

Fig. 3 Scatter plot of the relationship between genetic and geographic distances. No significant correlation between genetic differentiation and geographic distance among Anopheles arabiensis populations

general in agreement with the $\mathrm{F}_{\mathrm{ST}}$ analyses where $\mathrm{Kr}$ and to a lower degree, Se are distant from the other populations although My is closely related to the latter. In the $\mathrm{F}_{\mathrm{ST}}$ analysis, $\mathrm{Kr}$ and Se were also found to be genetically distant. However, the phylogenetic tree showed that only $\mathrm{Kr}$ is distant from the other populations. On the other hand, An. arabiensis populations from $\mathrm{Hj}, \mathrm{GW}$ and $\mathrm{H} . \mathrm{sh}$; My and Se are highly related genetically (Fig. 6).

\section{Discussion}

Allele frequency and linkage disequilibrium

In this study, a set of seven microsatellite markers, specific for An. gambiae [12] was used to analyse the population genetics among six An. arabiensis populations in Sudan. Allele number per locus ranging from 2 to 12 with an average of 7.6 alleles per locus as well as heterozygosity levels are concordant with other studies in this species conducted in Central Kenya and Madagascar [16] and Eastern Africa [25]. But higher heterozygosity values

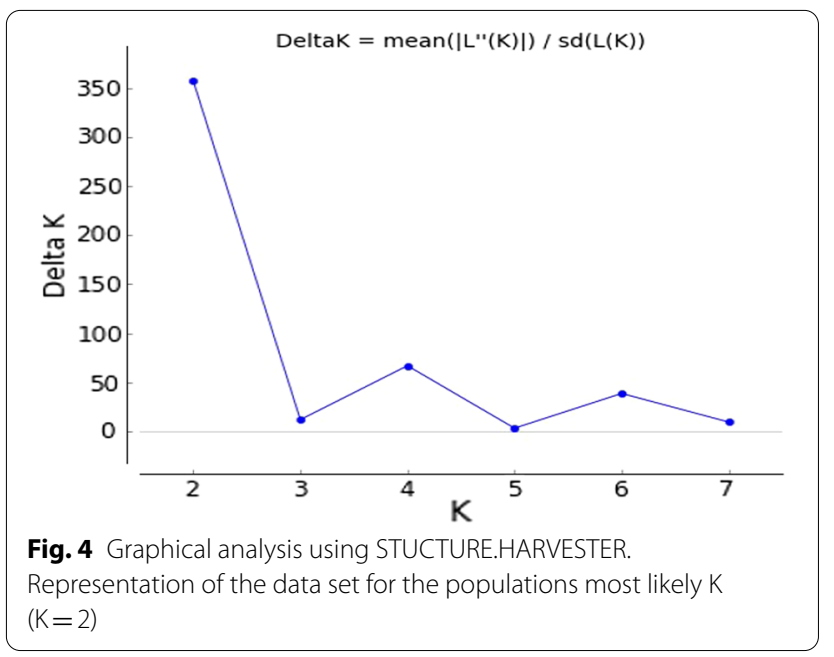




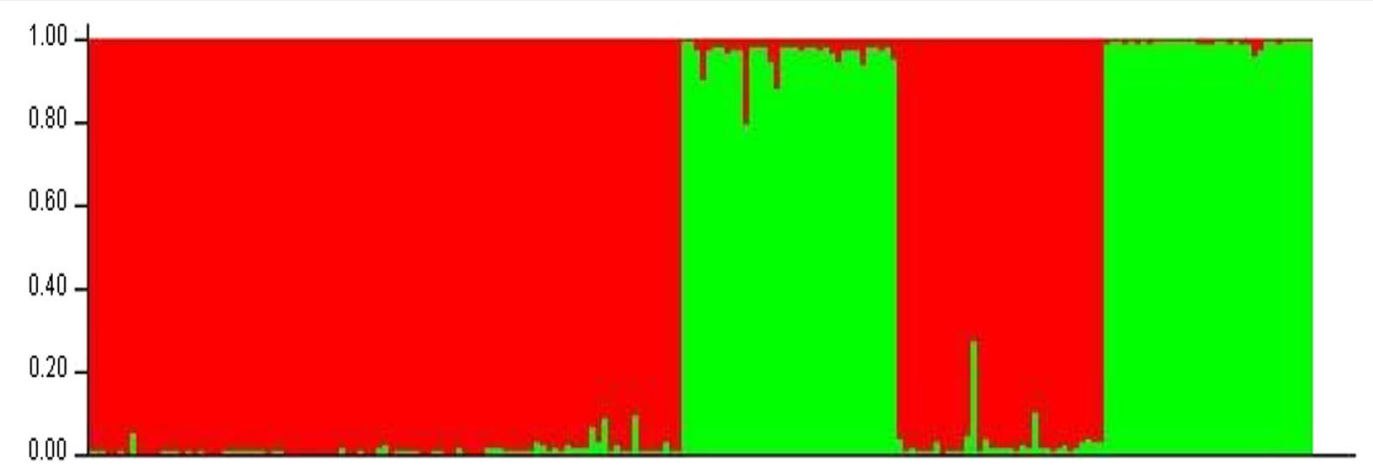

Fig. 5 Graphical Bayesian cluster analysis using STRUCTURE. Representation of the data set for the most likely $\mathrm{K}(\mathrm{K}=2)$, where each colour corresponds to a suggested cluster. Subpopulation A (red colour) includes Hj, Gw, My and H.sh populations and subpopulation B (green colour) includes Se and Kr populations

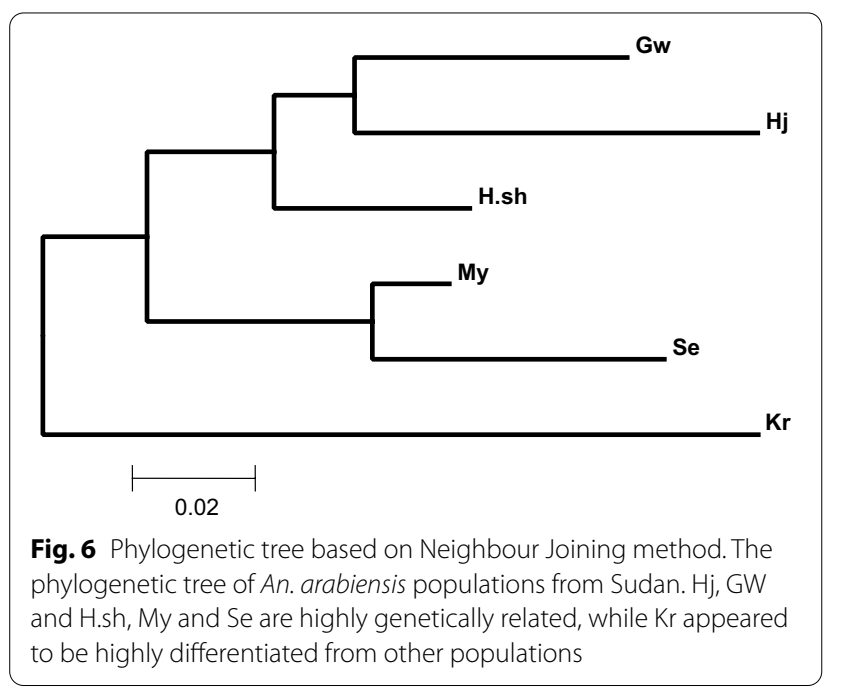

were observed in the eastern Africa Islands of Reunion and Mauritius [24, 27]. Similar values have also been obtained for other species for example in An. gambiae s.s. [35], An. funestus in east and southern Africa [53] and Anopheles atroparvus [54] in southern Europe. Muturi et al. [16] suggested that the level of allelic polymorphism could provide powerful measures to identify population subdivision.

Analyses of linkage disequilibrium on six An. arabiensis populations in Sudan suggest the existence of population subdivision. Similarly, using a different suite of microsatellite markers for An. arabiensis in Southern Tanzania, Ng'habi et al. [17] observed high linkage disequilibrium which they attributed to the presence of population subdivision. The significant linkage disequilibrium observed in this study could be attributed to heterozygote deficits due to several factors-departure from random mating as a result of inbreeding or selection for certain genotypes following ecological and environmental changes.

\section{Population differentiation and population structure}

The population pairwise $\mathrm{F}_{\mathrm{ST}}$ values of 0.06 to 0.24 and STRUCTURE analysis of $K=2$, divided the six populations into two groups; comprising of $\mathrm{Kr}$ (Kassala State) and Se (Sennar State) in one group and H.sh, My, Hj and Gw (located in Khartoum and Kassala states) in another The $\mathrm{F}_{\mathrm{ST}}$ from pooled loci reported in this study was in concordance with the reported $\mathrm{F}_{\mathrm{ST}}$ values for $A n$. arabiensis from Ethiopia and Eritrea [13]. Both studies detected low $\mathrm{F}_{\mathrm{ST}}$ but statistically significant genetic structure in An. arabiensis populations. However, Donnelly and Townson [25] did not detect significant genetic structure for An. arabiensis populations within Malawi and Sudan. Chen et al. [55] also detected a low, but significant, genetic structure of An. gambiae in Lake Victoria islands $\left(\mathrm{F}_{\mathrm{ST}}=0.019\right)$ and among the six villages in the mainland $\left(\mathrm{F}_{\mathrm{ST}}=0.010\right)$. This shows that structuring pattern is influenced by numerous factors specific to the geographic locations.

In particular, a high level of genetic differentiation was found in An. arabiensis involving certain populations in comparison with $(\mathrm{Kr})$ in the current study, in agreement with that observed between the Reunion and Mauritius Islands ( $\mathrm{F}_{\mathrm{ST}}$ ranged from 0.080 to 0.215$)$, located $240 \mathrm{~km}$ apart in East Africa Simard et al. [27]. Similarly, high levels of genetic differentiation was detected among An. arabiensis populations (mean $\mathrm{F}_{\mathrm{ST}}=0.066$ ) [17]. This was not in agreement with An. gambiae s.s. (mean $\mathrm{F}_{\mathrm{ST}}=0.006$ ) which was genetically undifferentiated across the $6650 \mathrm{~km}^{2}$ of the Kilombero valley landscape in southern Tanzania. Kayondo et al. [56] studied genetic structure of An. gambiae populations among islands in north-western Lake Victoria, Uganda with $\mathrm{F}_{\mathrm{ST}}$ ranging from 0.014 
to 0.105 and concluded that these populations were significantly genetically differentiated [54]. Similar to $\mathrm{F}_{\mathrm{ST}}$ values of 0.20 and 0.30 as described by Vicente et al. [54], Kamau et al. [57] observed $\mathrm{F}_{\mathrm{ST}}$ values of 0.25 while Walton et al. [58], who studied genetic population structure and introgression in Anopheles dirus in South-east Asia reported $\mathrm{F}_{\mathrm{ST}}$ value of $0.21-0.39$. These studies highlight that pattern of population structuring may differ when comparing different sets of populations in A. gambiae as well as in other mosquito species.

The high differentiation of $\mathrm{Kr}$ from the other populations may be due to its ecology which was far from agriculture areas compared to the rest which were near or within agriculture areas. $\mathrm{Kr}$ population is presumably reproductively isolated due to non-random mating or ecologically isolated as an effect of the AlGash River which acts as a physical barrier separating $\mathrm{Kr}$ from other populations. Hemming-Schroeder et al. [59] found that cropland was an important ecological driver for gene flow of An. arabiensis. In agreement with this postulate, $\mathrm{Kr}$ which is far from any agricultural areas was instead highly differentiated from other populations. Coluzzi [60], hypothesized that inversions may play an important role in the isolation process among species in the $A n$. gambiae complex and between the various forms of $A n$. gambiae s.s. He postulated that inversions can group coadapted gene complexes that confer adaptation in temporarily isolated peripheral populations with marginal ecological conditions. When secondary contact with the source population occurs, these inversions protect the co-adapted gene complexes from recombination, resulting in stable inversion polymorphisms and/or expansions of the population into new habitat, finally resulting in a more permanent isolation and differentiation.

High genetic similarity between $\mathrm{My}$ and $\mathrm{Hj}$ which are geographically close to each other was observed, suggesting that they may represent a single population or gene pool. According to Francois et al. [47], neighbouring populations are expected to be genetically more related than distant populations and high gene flow generally prevent local adaptation. Consequently, human transportation or wind dispersal may be the reason behind the continuous gene flow between these two localities and to a lower degree, two others namely GW and H.sh. The high gene flow found between these particular populations in this study is interesting with regards to the spread of insecticide resistance in Sudan as in consequence it also facilitated the movement of resistant mosquitoes across these connected populations. This is concordant with Kent et al. [15], who studied spatial and temporal genetic structure of An. arabiensis in Southern Zambia. They observed high gene flow between Macha and Namwala populations, in Southern Zambia. This is also in agreement with Muturi et al. [16], who found high gene flow among the three populations of An. arabiensis in Central Kenya. Failloux et al. [61] detected a significant correlation between gene flow and commercial traffic by planes and/or boats between islands on Aedes polynesiensis populations from islands in French Polynesia. These studies show that although the species can only fly within a limited distance, passive transportation could facilitate genetic homogeneity among distant populations.

The Mantel test showed no evidence of isolation by distance in this study, similar with that reported by Nyanjom et al. [13] in populations of An. arabiensis from Ethiopia and Eritrea. Isolation by distance could occur due to the limited flight range of An. arabiensis [62], but this was not the case for this study. It is known that the distributional range of any species is largely shaped by historical and geographical events. The species will extend its range until it reaches a physical (mountain ranges, deserts and major geographic feature) or other forms of barriers (example climatic changes). However, there are no variable ecological zones, or great physical barriers which could have led to population structuring. These results points to great impact of transportation in the genetic structure of An. arabiensis along the River Nile. Thus, presumably, the differentiation could largely be due to other factors than geographic distance. A similar observation was seen within An. atroparvus [54], where no correlation between geographic or genetic distances was detected in a study conducted in southern Europe. In agreement, Kamau et al. [21], using microsatellite loci, revealed that there were no significant relationship between geographic and genetic distances in An. arabiensis and An. gambiae, suggesting that levels of genetic differentiation are not related to geographical distance and not associated to the side on which populations were sampled in relation to the Rift Valley. Chen et al. [55] who studied population genetic structure of $A n$. gambiae mosquitoes on Lake Victoria islands, west Kenya revealed a significant correlation between geographic distance and pairwise distance. On the other hand, Failloux et al. [61] found no significant effect of geographic distance on the population genetic structure on Aedes polynesiensis populations from islands in French Polynesia in contrast to the genetic structuring pattern of Culex pipiens quinquefasciatus from the same islands. In the latter species, genetic differentiation increased considerably $(\mathrm{p}<0.01)$ with geographic distance [62] These differences may be due to the variable biology of the two species as well as their histories of colonization. The current study concludes high continuous gene flow among the studied populations (except for $\mathrm{Kr}$ ), without any signs of isolation. The high migration rate and lack of interpopulation genetic variation among the Sudanese 
population is attributed to the continuous human and domestic animal movement among the studied localities that facilitated the distribution of An. arabiensis (with the exception of $\mathrm{Kr}$ ).

\section{Population size bottleneck}

No severe bottleneck or reduction in population size was detected in the An. arabiensis populations of Sudan, except in AlHajYousif (Hj). This was evident based on the significance in Wilcoxon sign-rank test which was also supported by the "shifted mode" allele distribution. In comparison, the other populations had relatively higher rare alleles than common alleles, a sign that these populations were experiencing mutation-drift equilibrium. The situation at AlHaj Yousif $(\mathrm{Hj})$ is likely due to the effective vector control programme in this area. This finding does not agree with Muturi et al. [16], who studied the population genetic structure of An. arabiensis in central Kenya. They did not find any evidence of genetic bottlenecks in the area under different agricultural practices. Furthermore, there was no evidence of a genetic bottleneck in An. arabiensis despite a drastic reduction in mosquito numbers during the drought year in southern Zambia as reported by Kent et al. [15]. This is similar to the present study, where there is a reduction in $\mathrm{An}$. arabiensis during the dry season but no occurrence of genetic bottlenecks apart from $\mathrm{Hj}$ which is under vector control programmes. $\mathrm{Hj}, \mathrm{My}$ and $\mathrm{Gw}$ in Khartoum state have very strong programmes of malarial control, the 'Khartoum Malaria Free Initiative' started from 2001 to 2009. The significant achievement in malarial control in Khartoum state is highly evident. For example, the percentage of malaria cases among the followers of health services decreased from 20\% in 2001 to just 3.3\% in 2008 and the parasitological incidence went down from 91 to just 4 per 10,000 population. Another programme was initiated in 2011 and is due to end in 2015. The objective of this initiative is to decrease malaria mortality and morbidity. Specifically, the initiative aims to reduce malaria cases by 90\% by 2015 in northern Sudan compared to the number of reported cases in 2009. However, results of this study in My and Gw did not show any reduction. This could be explained due to the resistance to insecticide. Therefore, this lack of reduction in these populations suggests that they are still expanding.

Present literature on An. arabiensis has revealed the lack of subpopulation differentiation in relation to larval habitat utilization [22]. Lack of annual bottlenecks in response to changes in the environment has also been documented [15, 24]. Large effective population size and/ or recent range expansion as opposed to group migration $[24,25]$ have been attributed to the lack of population structuring. This is based on several experimental studies which have reported a short flight range for this malaria vector species [26] among villages in Gambia. On the other hand, there is evidence in support of population structuring [27] from West Africa and eastern outer islands [27] of Eastern Africa. Furthermore, limited gene flow has been observed between the west and south east of the Rift Valley and in Southern Zambia [15, 21], respectively. Thus, while An. arabiensis displays panmixia when population numbers are high, this can be reversed when inter population geographic distances are high and habitat alterations occur, leading to genetic isolation.

Microsatellite markers analysis showed that high linkage disequilibrium detected between loci and high genetic differentiation was observed between $A n$. arabiensis populations from $\mathrm{Kr}$ and other populations $\mathrm{F}_{\mathrm{ST}}=0.17-0.24$. Therefore, $\mathrm{Kr}$ populations were more genetically isolated from the rest and from each other. Additionally, $\mathrm{Kr}$ may be reproductively isolated due to non-random mating or movement of people from Ethiopia to Sudan. It could also be ecologically isolated as a consequence of the $\mathrm{Al} \mathrm{Gash} \mathrm{River} \mathrm{which} \mathrm{acts} \mathrm{a} \mathrm{as} \mathrm{a}$ physical barrier separating $\mathrm{Kr}$ from other populations. Therefore, $\mathrm{Kr}$ is easier to control compared to other populations. High gene flow was detected among Se (Sennar State) with My and Gw (both Khartoum State); $\mathrm{Hj}$ and My (both Khartoum State). Very little gene flow was observed between $\mathrm{Kr}$ (Kassala State) and other populations. All populations had not experienced population bottleneck. However, population $\mathrm{Hj}$ with shifted mode suggest recent population size reduction. The phylogenetic tree showed that populations $\mathrm{Hj}, \mathrm{GW}$ and H.sh, My and Se are genetically closely related, while $\mathrm{Kr}$ appeared to be comparatively differentiated from other populations.

\section{Conclusion}

This study concluded that genetic analysis revealed high population panmixia and continuous gene flow among the studied populations, without any signs of isolation apart from the $\mathrm{Kr}$, presumably due to ecological barriers. The high migration rate and lack of interpopulation genetic variation among the Sudanese population was attributed to the continuous human and domestic animal movements among the studied localities that facilitated distribution of An. arabiensis. However, as discussed, both abiotic (e.g. passive transportation) and biotic (e.g. chromosome inversion) factors may influence the genetic structuring of mosquito species populations. As such, where possible it is recommended that an important consideration of any population genetics study is also to understand the underlying reasons for the pattern observed. More extensive studies on population structure and genetics of An. arabiensis in the other regions of 
Sudan using additional microsatellite loci are required to elucidate the factors that may affect gene flow for strategizing management and control of mosquito infestation in the country.

\section{Abbreviations}

An: Anopheles; PCR: Polymerase chain reaction; IGS: Intergenic spacer; HWE: Hardy Weinberg equilibrium; FDR: False discovery rate; IAM: Infinite allele model; TPM: Two phase models; SMM: Stepwise mutation; IRS: Indoor residual spray; ITNs: Insecticide treated bed nets.

\section{Acknowledgements}

This project was mainly supported by the Postgraduate Research Grant Scheme (USM- RU-PRGS) of the Universiti Sains Malaysia. Thanks also go to TWAS for providing the PhD fellowship, and to the Unversity of Albutana for granting me the study leave. Special thanks go to the Zoology Department, Faculty of Science, University of Khartoum and the Malaria Research Center in Sennar for allowing me to use their laboratory and the technical assistance given during the period of the study and all members of Lab 308, School of Biological Sciences, Universiti Sains Malaysia.

\section{Authors' contributions}

MSM: did the field and practical laboratory work, data analyses and prepared the manuscript. ZJ and SAMN supervised the study and edited the manuscript. SA supervised the field work. All authors read and approved the final manuscript.

\section{Funding}

This work funded by TWAS-USM Postgraduate Fellowship FR number:

3240189425 for the first Authors Ph.D.

\section{Availability of data and materials}

All data generated or analysed during this study are included in the text.

\section{Declarations}

Ethics approval and consent to participate

Not applicable.

\section{Consent for publication}

Not applicable.

\section{Competing interests}

The authors declare that they have no competing interests.

\section{Author details}

'Department of Biology \& Chemistry, Al Butana University, 200, Rufaa, Sudan. ${ }^{2}$ School of Biological Sciences, Universiti Sains Malaysia, 11800 Penang, Malaysia. ${ }^{3}$ Faculty of Science, Department of Zoology, University of Khartoum, Khartoum, Sudan. ${ }^{4}$ Institute of Marine Biotechnology, Universiti Malaysia Terengganu, 21030 Kuala Terengganu, Malaysia.

Received: 14 December 2020 Accepted: 25 November 2021 Published online: 19 December 2021

\section{References}

1. El Sayed BB, Nugud AD. A study of the urban malaria transmission problems in Khartoum. Acta Trop. 2000;74:163-71.

2. Petrarca V, Nugud AD, Ahamed MA, Haridi AM, Di Deco MA, Coluzzi M. Cytogenetics of An. arabiensis relationships with East and West African populations. Med Vet Entomol. 2000;14:149-64.

3. Himeidan Y, Dukeen M, EL-Rayah A, Adam I. Anopheles arabiensis: abundance and insecticide resistance in an irrigated area of eastern Sudan. East Mediterr Health J. 2004;10:167-74.
4. Abdalla H, Matambo TS, Koekemoer LL, Mnzavae AP, Hunt RH, Coetzee M. Insecticide susceptibility and vector status of natural populations of Anopheles arabiensis from Sudan. Trans R Soc Trop Med Hyg. 2008;102:263-71.

5. Osman TA. Species identification and infectivity rate of malaria vector in two endemic malaria areas in Sudan. Egypt Acad J Biol Sci. 2010;2:1-15.

6. Seidahmed OME, Abdelmajed MA, Mustafa MS, Mnzava AP. Insecticide susceptibility status of the malaria vector Anopheles arabiensis in Khartoum city, Sudan: differences between urban and periurban areas. East Mediterr Health J. 2012;8:769-76.

7. Yagoop JES, Bashir NH, Assad YO. Susceptibility of Anopheles arabiensis (Diptera: Culicidae) adults to some commonly used agricultural insecticides in El Rahad Agricultural Corporation, Central Sudan. Sch J Agric Sci. 2013;3:10-20.

8. Muturi J, Muriu S, Shililu J, Mwangangi J, Jacob B, Mbogo C, et al. Effect of rice cultivation on malaria transmission in central Kenya. Am J Trop Med Hyg. 2008:78:270-5.

9. Mwangangi J, Muturi J, Shililu J, Muriu S, Jacob B, Kabiru E, et al. Contribution of different aquatic habitats to adult Anopheles arabiensis and Culex quinquefasciatus (Diptera: Culicidae) production in a rice agroecosystem in Mwea, Kenya. J Vector Ecol. 2008;33:129-38.

10. Lengeler $C$. Insecticide-treated bed nets and curtains for preventing malaria. Cochrane Database Syst Rev. 2004;2:CD000363.

11. Fegan GW, Noor AM, Akhwale WS, Cousens S, Snow RW. Effect of expanded insecticide-treated bednet coverage on child survival in rural Kenya: a longitudinal study. Lancet. 2007;370:1035-9.

12. Zheng L, Benedict MQ, Cornel AJ, Collins FH, Kafatos FC. An integrated genetic map of the African human malaria vector mosquito Anopheles gambiae. Genetics. 1996;143:941-52.

13. Nyanjom SR, Chen H, Gebre-Michael T, Bekele E, Shililu J, Githure J, et al. Population genetic structure of Anopheles arabiensis mosquitoes in Ethiopia and Eritrea. J Hered. 2003;94:457-63.

14. Temu EA, Yan G. Microsatellite and mitochondrial genetic differentiation of Anopheles arabiensis (Diptera: Culicidae) from western Kenya, the Great Rift Valley, and coastal Kenya. Am J Trop Med Hyg. 2005;73:726-33.

15. Kent RT, Mharakurwa S, Norris DE. Spatial and temporal genetic structure of Anopheles arabiensis in Southern Zambia over consecutive wet and drought years. Am J Trop Med Hyg. 2007;77:316-23.

16. Muturi J, Kim C, Baliraine F, Musani S, Jacob B, Githure J, et al. Population genetic structure of Anopheles arabiensis (Diptera: Culicidae) in a rice growing area of central Kenya. J Med Entomol. 2010;47:144-51.

17. Ng'habi KR, Knols BG, Lee Y, Ferguson HM, Lanzaro GC. Population genetic structure of Anopheles arabiensis and Anopheles gambiae in a malaria endemic region of southern Tanzania. Malar J. 2011;10:289.

18. Deitz KC, Athrey G, Reddy MR, Overgaard HJ, Matias A, Jawara M, et al. Genetic isolation within the malaria mosquito Anopheles melas. Mol Ecol. 2012;21:4498-513.

19. Aransay AM, Ready PD, Morillas-Marquez F. Population differentiation of Phlebotomus perniciosus in Spain following postglacial dispersal. Heredity (Edinb). 2003;90:316-25.

20. Zheng L, Collins FH, Kumar V, Kafatos FC. A detailed genetic map for the $\mathrm{X}$ chromosome of the malaria vector Anopheles gambiae. Science. 1993;261:605-8.

21. Kamau L, Mukabana WR, Hawley WA, Lehmann T, Irungu LW, Orago AA, et al. Analysis of genetic variability in Anopheles arabiensis and Anopheles gambiae using microsatellite loci. Insect Mol Biol. 1999;8:287-97.

22. Kamau L, Munyekenye GO, Vulule JM, Lehmann T. Evaluating genetic differentiation of Anopheles arabiensis in relation to larval habitats in Kenya. Infect Genet Evol. 2007;7:293-7.

23. Moreno M, Salgueiro P, Vicente JL, Cano J, Berzosa PJ, de Lucio A, et al. Genetic population structure of Anopheles gambiae in Equatorial Guinea. Malar J. 2007;6:137.

24. Simard F, Lehmann T, Lemasson JJ, Diatta M, Fontenille D. Persistence of Anopheles arabiensis during the severe dry season conditions in Senegal: an indirect approach using microsatellite loci. Insect Mol Biol. 2000;9:467-79.

25. Donnelly MJ, Townson $\mathrm{H}$. Evidence for extensive genetic differentiation among populations of the malaria vector Anopheles arabiensis in Eastern Africa. Insect Mol Biol. 2000;9:357-67. 
26. Thomson MC, Connor SJ, Quinones ML, Jawara M, Todd J, Greenwood BM. Movement of Anopheles gambiae s.l. malaria vectors between villages in The Gambia. Med Vet Entomol. 1995;9:413-9.

27. Simard F, Fontenille D, Lehmann T, Girod R, Brutus L, Gopaul R, et al. High amounts of genetic differentiation between populations of the malaria vector Anopheles arabiensis from West Africa and eastern outer islands. Am J Trop Med Hyg. 1999;60:1000-9.

28. Mutero C, Kabutha C, Kimani V, Kabuage L, Gitau G, Ssennyonga J, et al. A transdisciplinary perspective on the links between malaria and agroecosystems in Kenya. Acta Trop. 2004;89:171-86.

29. Muturi J, Shililu J, Jacob B, Githure J, Gu W, Novak R. Mosquito species diversity and abundance in relation to land use in a riceland agroecosystem in Mwea, Kenya. J Vector Ecol. 2006;31:129-37.

30. Afrane YA, Zhou G, Lawson BW, Githeko AK, Yan G. Effects of microclimatic changes caused by deforestation on the survivorship and reproductive fitness of Anopheles gambiae in western Kenya highlands. Am J Trop Med Hyg. 2006;74:772-8.

31. Ijumba JN, Lindsay SW. Impact of irrigation on malaria in Africa: paddies paradox. Med Vet Entomol. 2001;15:1-11.

32. Toure YT, Petrarca V, Traore SF, Coulibaly A, Maiga HM, Sankare O, et al. Ecological genetic studies in the chromosomal form Mopti of Anopheles gambiae s.s. in Mali, west Africa. Genetica. 1994;94:213-23.

33. Toure YT, Dolo G, Petrarca V, Traore SF, Bouare M, Dao A, et al. Mark-release recapture experiments with Anopheles gambiae s.I. in Banambani village, Mali, to determine population size and structure. Med Vet Entomol. 1998;12:74-83.

34. Dolo G, Briet OJT, Dao A, Traore SF, Bouare M, Sogoba N, et al. Malaria transmission in relation to rice cultivation in the irrigated Sahel of Mali. Acta Trop. 2004;89:147-59.

35. Lehmann T, Hawley WA, Grebert H, Danga M, Atieli F, Collins FH. The Rift Valley complex as a barrier to gene flow for Anopheles gambiae in Kenya. J Hered. 1999;90:613-21.

36. Lehmann T, Licht M, Elissa N, Maega BT, Chimumbwa JM, Watsenga FT, et al. Population structure of Anopheles gambiae in Africa. J Hered. 2003;94:133-47.

37. Scott JA, Brogdon WG, Collins FH. Identification of single specimens of the Anopheles gambiae complex by the polymerase chain reaction. Am J Trop Med Hyg. 1993;49:520-9.

38. Arif IA, Khan HA, Shobrak M, Al Homaidan AA, Al Sadoon M, Al Farhan AH, et al. Interpretation of electrophoretograms of seven microsatellite loci to determine the genetic diversity of the Arabian Oryx. Genet Mol Res. 2010;9:259-65.

39. Van Oosterhout C, Hutchinson WF, Wills DM, Shipley P. Micro-checker: software for identifying and correcting genotyping errors in microsatellite data. Mol Ecol Notes. 2004;4:535-8.

40. Glaubitz JC. Convert: a user-friendly program to reformat diploid data for commonly used population genetic software packages. Mol Ecol Notes. 2004:4:309-10.

41. Slatkin $M$, Excoffier $L$. Testing for linkage disequilibrium in genotypic data using the EM algorithm. Heredity (Edinb). 1996;76:377-83.

42. Excoffier L, Laval G, Schneider S. Arlequin ver. 3.0: an integrated software package for population genetics data analysis. Evol Bioinform Online. 2007:1:47-50.

43. Benjamini Y, Hochberg Y. Controlling the false discovery rate: a practical and powerful approach to multiple testing. J R Stat Soc. 1995;57:289-300.

44. Weir BS, Cockerham CC. Estimating F-statistics for analysis of population structure. Evolution. 1984;38:1358-70.

45. Goudet J. FSTAT version 2.9.3.2. A computer software to calculate Fstatistics. J Hered. 1995;86:485-6.

46. Goodman SJ. RST Calc: a collection of computer programs for calculating estimates of genetic differentiation from microsatellite data and determining their significance. Mol Ecol. 1997;6:881-5.

47. Francois B, Nicolas LM. The estimation of population differentiation with microsatellite markers. Mol Ecol. 2002;11:155-65.

48. Piry S, Luikart G, Cornuet JM. Bottleneck: a computer software program for detecting recent reductions in the effective population size using allele frequency data. J Hered. 1999;90:502-3.

49. Evanno G, Regnauto S, Goudet J. Detecting the number of cluster of individuals using the software STRUCTURE A simulation study. Mol Ecol. 2005:14:2611-20.
50. Jakobsson M, Rosenberg NA. CLUMPP: a cluster matching and permutation program for dealing with label switching and multimodality in analysis of population structure. Bioinformatics. 2007;23:1801-6.

51. Earl DA, von Holdt BM. Structure harvester: a website and program for visualizing STRUCTURE output and implementing the Evanno method. Conserv Genet Resour. 2012;4:359-61.

52. Tamura K, Peterson D, Peterson N, Steche G, Nei M, Kumar S. MEGA5: molecular evolutionary genetics analysis using maximum likelihood, evolutionary distance, and maximum parsimony methods. Mol Biol Evol. 2011;28:2731-9.

53. Temu EA, Hunt RH, Coetzee M. Microsatellite DNA polymorphism and heterozygosity in the malaria vector mosquito Anopheles funestus (Diptera: (ulicidae) in east and southern Africa. Acta Trop. 2004;90:39-49.

54. Vicente JL, Sousa CA, Alten B, Caglar SS, Falcutá E, Latorre JM, et al. Genetic and phenotypic variation of the malaria vector Anopheles atroparvus in southern Europe. Malar J. 2011;10:5.

55. Chen H, Minakawa N, Beier J, Yan G. Population genetic structure of Anopheles gambiae mosquitoes on Lake Victoria islands, west Kenya. Malar J. 2004;3:48

56. Kayondo JK, Mukwaya LG, Stump A, Michel AP, Coulibaly MB, Besansky NJ, et al. Genetic structure of Anopheles gambiae populations on islands in northwestern Lake Victoria, Uganda. Malar J. 2005;4:59.

57. Kamau L, Hawley WA, Lehmann T, Orago AS, Cornel A, Ke Z, et al. Use of short tandem repeats for the analysis of genetic variability in sympatric populations of Anopheles gambiae and Anopheles arabiensis. Heredity (Edinb). 1998;80:675-82.

58. Walton C, Handley JM, Collins FH, Baimai V, Harbach RE, Deesin V, et al. Genetic population structure and introgression in Anopheles dirus mosquitoes in South-east Asia. Mol Ecol. 2001;10:569-80.

59. Hemming-Schroeder E, Zhong D, Machani M, Nguyen H, Thong S, Kahindi $\mathrm{S}$, et al. Ecological drivers of genetic connectivity for African malaria vectors Anopheles gambiae and An. arabiensis. Sci Rep. 2020;10:19946.

60. Coluzzi M. Spatial distribution of chromosomal inversions and speciation in anopheline mosquitoes. In: Barigozzi C, editor. Mechanisms of speciation. New York: Alan R. Liss, Inc.; 1982. p. 143-53.

61. Failloux AB, Raymond M, Ung A, Chevillon C, Pasteur N. Genetic differentiation associated with commercial traffic in the Polynesian mosquito, Aedes polynesiensis Marks 1951. Biol J Linnean Soc. 1997;60:107-18.

62. Adams PCG. Some observations on the flight of stained anophelines in Nkana, North Rhodesia. Ann Trop Med Parasitol. 1940:34:35-43.

\section{Publisher's Note}

Springer Nature remains neutral with regard to jurisdictional claims in published maps and institutional affiliations.

Ready to submit your research? Choose BMC and benefit from

- fast, convenient online submission

- thorough peer review by experienced researchers in your field

- rapid publication on acceptance

- support for research data, including large and complex data types

- gold Open Access which fosters wider collaboration and increased citations

- maximum visibility for your research: over 100M website views per year

At BMC, research is always in progress.

Learn more biomedcentral.com/submissions 